\title{
Unilateral Renal Agenesia Associated with Partial Epididymis and Vas Deferens Agenesia in a Patient with Abdominal Testicle
}

\author{
Joao L. Pippi Salle, Jacob Langer, Luciano A. Favorito \\ Department of Urology, Hospital for Sick Children, University of Toronto, Toronto, Canada
}

\begin{abstract}
This study considers a unilateral renal agenesia associated with agenesia of the epididymis body and tail and the vas deferens and non-palpable left testicle in a 20-month-year-old patient. During laparoscopic procedure, the testicle was positioned at approximately $5 \mathrm{~cm}$ above the inguinal ring. The size was appropriate for the age and the head of the epididymis was situated in its normal position. The decision was made to perform the first step of the Fowler-Stephens' surgery and the patient presented a good evolution. The association of male duct system agenesia with unilateral renal agenesia in a patient with cryptorchidism diagnosed by laparoscopy is an extremely rare event, however generally in these cases the testicle is of normal size, presents unaltered hormonal function, and must be preserved.
\end{abstract}

Key words: testis; cryptorchidism; kidney; urogenital anomalies

Int Braz J Urol. 2006; 32: 208-10

\section{INTRODUCTION}

Urinary and genital systems originate in the intermediary mesoderm located along the posterior wall of the abdominal cavity between the fourth and the tenth week post-conception (1). Alterations in this development before the fourth week can lead to unilateral agenesia of the genitourinary structures (1).

The occurrence of duct anomalies (epididymis, vas deferens, ejaculatory ducts and seminal vesicles) is very frequent in infertile patients and in cryptorchidism $(1,2)$. However, reports of partial agenesia of the epididymis associated with vas deferens and renal agenesia in patients with abdominal testicle is extremely rare. The objective of the present article is to discuss the occurrence of unilateral renal and genital duct agenesia in a patient with an abdominal testicle located during a laparoscopic diagnosis procedure.

\section{CASE REPORT}

We discuss the case of a twenty-month-old patient with a non-palpable left testicle and topic right testicle of normal size for his age who presented no other significant alterations during the physical exam. An abdominal ultrasound showed the left testicle in an intra-abdominal position. The patient was submitted to laparoscopic orchidopexy, which revealed the left testicle situated around $5 \mathrm{~cm}$ above the internal inguinal ring.

During the procedure, we noticed the absence of the left vas deferens (Figure-1) and agenesia of the epididymis body and tail (Figures-2 and 3 ) and also of the left kidney. The epididymis head was in its normal situation (Figure-2). As the testicle was of a normal size, we decided to perform the FowlerStephens surgery in 2 steps - clamping of the spermatic vessels first with the second step (orchidopexy) 


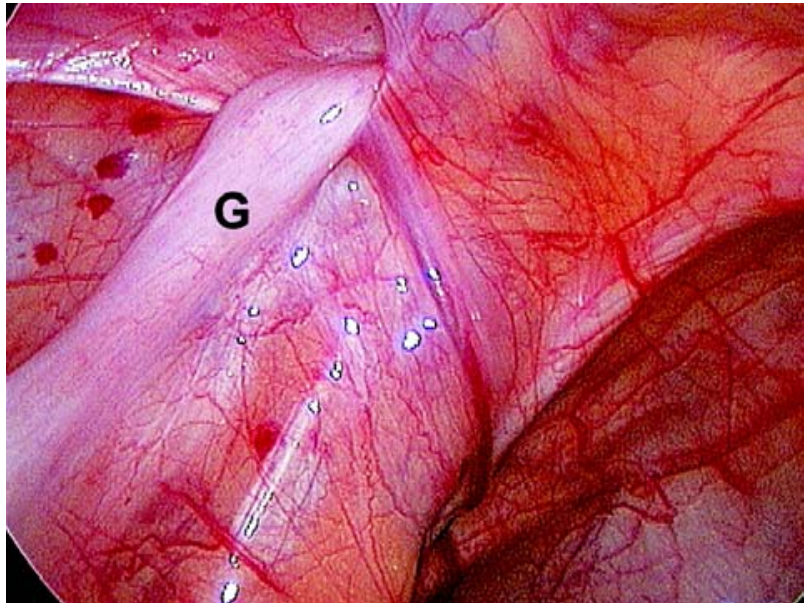

Figure 1 - Laparoscopic view of the internal inguinal ring. We observe the testicular gubernaculum and vessels crossing the inguinal ring; the deferent duct is not identified. $G=$ gubernaculum.

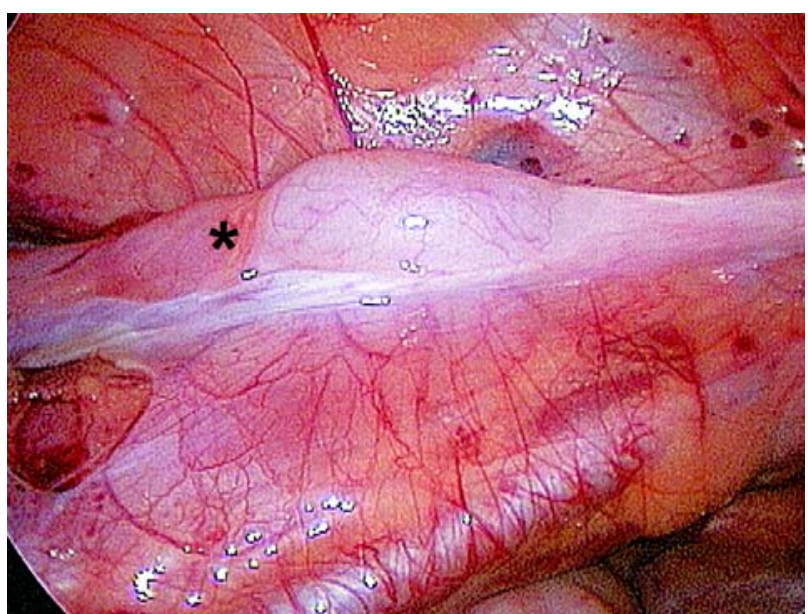

Figure 2 - Laparoscopic view of the left testicle where we observe the epididymis head $(*)$.

after 6 months. The patient evolved well and was discharged the day after the procedure.

\section{COMMENTS}

Anomalies of the epididymis and the vas deferens can be divided into 2 groups: (a) anomalies associated with cryptorchidism and (b) anomalies observed during infertility investigations. Anomalies of

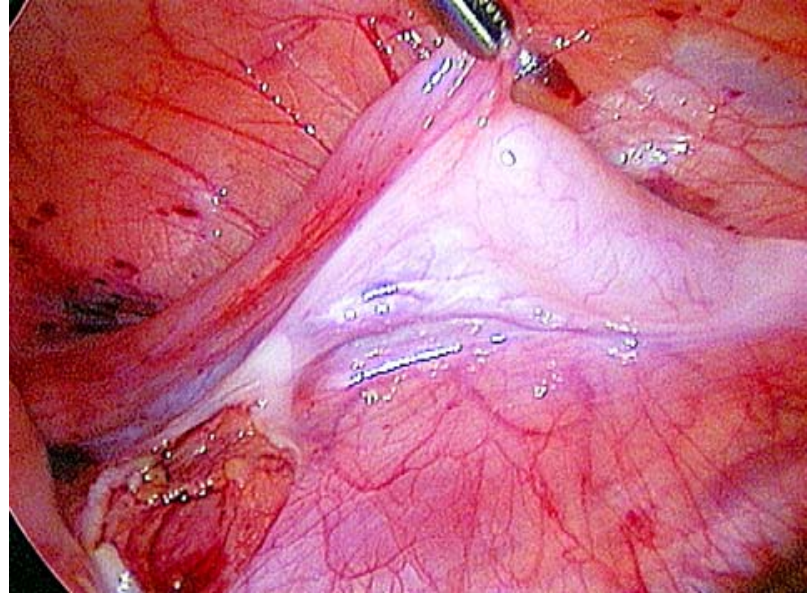

Figure 3 - Laparoscopic view of the left testicle. When we were mobilizing the testicle, we noticed the absence of the epididymis body and tail.

the epididymis are associated with cryptorchidism in 36 to $72 \%$ of cases (2); however, the existence of epididymis agenesia is one of the rarest epididymis anomalies (2).

Partial agenesia of the epididymis with its head in the habitual position can be explained by alterations in vascularization during the period of mesonefric tubules development before its fusion with the testicular tubules (3).

Renal anomalies in cryptorchidism present an incidence rate similar to the general population, with renal agenesia being one of the most common (1). Of patients with unilateral renal agenesia, 10 to $15 \%$ present genital anomalies, and of these patients with genital anomalies, the testicle is generally normal with an occurrence of partial agenesia of the epididymis and of the deferent in $50 \%$ of cases (1). In rare cases of cryptorchidism where there is a renal and epididymis agenesia, the testicle generally is normally sized and presents unaltered hormone function, therefore, must be preserved, even though the reproductive function is compromised.

\section{CONFLICT OF INTEREST}

None declared. 


\section{REFERENCES}

1. Favorito LA, Cardinot TM, Morais AR, Sampaio FJ: Urogenital anomalies in human male fetuses. Early Hum Dev. 2004; 79: 41-7.

2. Barthold JS, Redman JF: Association of epididymal anomalies with patent processus vaginalis in hernia, hydrocele and cryptorchidism. J Urol. 1996; 156: $2054-$ 6.

3. Gill B, Kogan S, Starr S, Reda E, Levitt S: Significance of epididymal and ductal anomalies associated with testicular maldescent. J Urol. 1989; 142: 556-8; discussion 572.

Correspondence address:

Dr. Luciano Alves Favorito

Rua Professor Gabizo, 104/201

Rio de Janeiro, RJ, 20271-320, Brazil

Fax: + $55213872-8802$

E-mail: favorito@uerj.br 